\title{
A STUDY ON CENSUS OF LARGE HERBIVOROUS MAMMALS DURING DRY SEASON IN MUDUMALAI WILDLIFE SANCTUARY, SOUTHERN INDIA
}

\author{
Surendra Varma and S. Asokan \\ Asian Elephant Research and Conservation Centre, Centre for Ecological Sciences, Indian Institute of Science, Malleswaram, Bangalore, \\ Karnataka 560012, India. \\ Email:varma@ces.iisc.ernet.in
}

\begin{abstract}
A census was carried out during January-April, 1988 in Mudumalai Wildlife Sanctuary to determine the density and number of large mammals during the dry season. Walking and vehicle transects were used in four different habitat types in the study area. The total number of animals sighted were recorded and density was calculated. The Spotted Deer density was very low in riverine forests. Sambar Deer were distributed in all habitats. Elephants were common in swampy areas and were not sighted in scrub jungle. The density of Gaurs was quite low. The Spotted Deer density was higher along the roadside than the dry deciduous forest whereas, Sambar Deer and Elephants were found more inside the forest. These results also show the habitat utilisation of these animals. Accuracy in the estimation of the density of all the animals is very difficult. Therefore it is best to use a combination of walking transects inside the forest and road transects. Since the number of animals also varies according to seasons it would be appropriate to divide the study area by habitat type before the census.
\end{abstract}

\section{Keywords}

Census, line transect, vehicle transect, density, animals, Mudumalai Wildlife Sanctuary, dry season

\section{Introduction}

Estimation of animal abundance is linked with utilization of habitat, rate of increase, dispersal and reaction of a population to management treatments. But estimating animal densities in the forest is complicated due to numerous practical field problems (Anderson et al., 1979). Some census results suffer from lack of trained manpower, lack of care to avoid duplicate counting resulting in artificially inflated census figures (Sale \& Johnsingh,
1988). Many methods of censusing assume a random distribution of animals or at least random orientation of transect lines. In the field, animals may have a distinctly clumped distribution. One example is the Axis Deer (Axis axis), which congregates near forest grassland ecotones and near human settlements (Sharatchandra \& Gadgil, 1975). It may not be always practical to lay transect lines at random.

The mode of carrying out transect census may also influence the results. If an observer walks on a transect, the animal may detect the observer's presence through sight or smell and move away before they are counted. If the observer goes by a vehicle the sound of the vehicle may influence the animal's reaction. Another problem is the intensity of sampling needed to achieve satisfactory results. In the course of walking transects there may not be sufficient sightings since the total distance covered is limited. If longer distances are covered, it may increase the sample size and a vehicle may be used for the purpose.

Studies were carried out during the dry season (January to April, 1988) in Mudumalai Wildlife Sanctuary to determine the factors influencing density estimates of the common large mammals like the Elephant (Elephas maximus), Gaur (Bos gaurus), Spotted Deer (Axis axis) and Sambar (Cervus unicolor).

The objective of the exercise was to determine the following: - The densities and numbers of these large mammals in different habitats during the dry season as per different methods,

- To compare estimates by walking transects with those from vehicle transects,

- The reasons for major differences in estimates if any,

- To find out if some mammals show an association for roadside as compared to their natural densities within forest, and - To determine the utilization of various habitats by large mammals in Mudumalai Wildlife Sanctuary during dry season. 


\section{Materials and Methods}

\section{Study area}

The Mudumalai Wildlife Sanctuary is situated in the Nilgiris of Tamil Nadu in southern India and it is included under the Nilgiri Biosphere Reserve. The Sanctuary lies between $11^{0} 13^{\prime}$ to $11^{0} 39^{\prime} \mathrm{N}$ and $76^{\circ} 27^{\prime}$ to $76^{\circ} 43^{\prime} \mathrm{E}$ and comprises a total area of $312 \mathrm{~km}^{2}$. It is one of the northern eastern slopes of the Nilgiri range and lies at an elevation between $1265 \mathrm{~m}$ and $625 \mathrm{~m}$. The rainfall varies from year to year and also from location to location. The annual figures are from $900 \mathrm{~mm}$ to $1800 \mathrm{~mm}$.

The flora of the Sanctuary is mixed deciduous, more moist in western-most Benne area and dry deciduous on its east. The Kargudi area and adjoining Mudumalai block have swampy grasslands, the Moyar River, Imberhalla and Bidarhalla rivers form the riverine forests. In the Moyar-Masinagudi area most of the shrubs and trees are thorny. Spotted Deer, Sambar, Elephants and Gaur are the main mega-mammalian fauna of the Sanctuary. This Sanctuary plays an important role in tourism, which gives way to the inroads for motor vehicles.

1 - Masinagudi; 2 - Theppakadu; 3 - Kargudi; - Water holes; CR - Circular road; CCR - Cross cut road; GHR - Game hunt road; MKR - Mudumalai Kakkanalla road; KMR - Kargudi Mudumalai road; UR - 'U' road; TMR - TheppakaduMudumalai road; MR - Mysore road; PR - Ponnangiri road; OR - Ombetta road; SR - Sand road; KR - Kargudi road; MTR - Masinagudi -Theppakadu road; JA - Jayadev avenue; MO'R - Moyar road

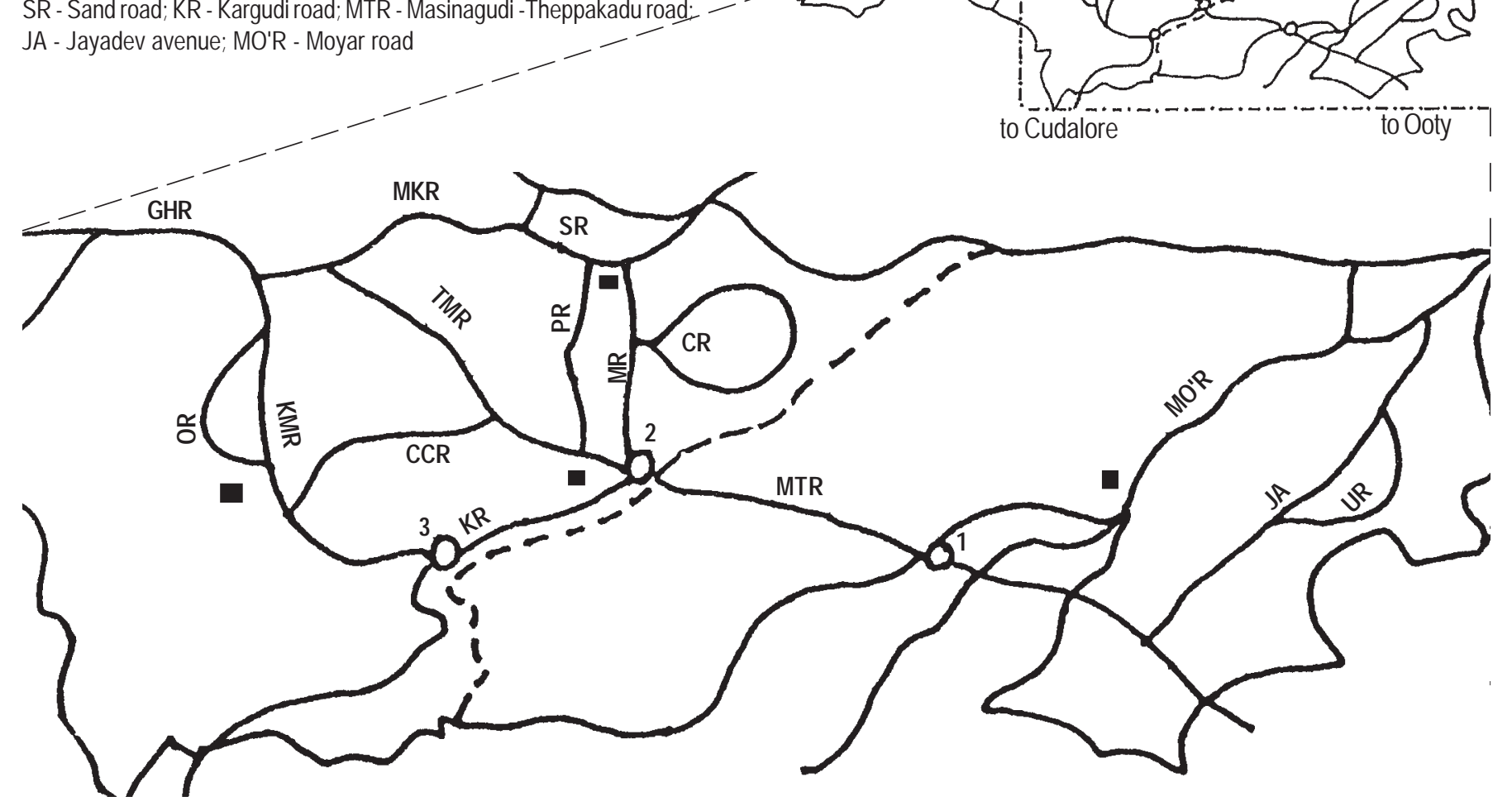

In the present study mainly the density of large mammals was estimated using walking and vehicle transects in four different habitat types in the study area. The habitats are dry deciduous forest, scrub forest, riverine and associated forest and swampy grasslands.

\section{Location of walking and vehicle transects in four different habitats}

Walking transects: In the dry deciduous forest, perpendicular to the Theppakadu-Mudumalai road, four $500 \mathrm{~m}$ long transects were laid at $500 \mathrm{~m}$ interval. Apart from these transects, the $2000 \mathrm{~m}$ long Theppakadu -Mudumalai road was also used as a transect. In the scrub forest perpendicular to the Jayadev avenue four $500 \mathrm{~m}$ long transects were laid at $500 \mathrm{~m}$ interval and the $2 \mathrm{~km}$ Jayadev Avenue was also used as a transect. The riverine forest selected for transect was the $2 \mathrm{~km}$ long path, which runs along the Moyar River. Ombetta swamp road was used as walking

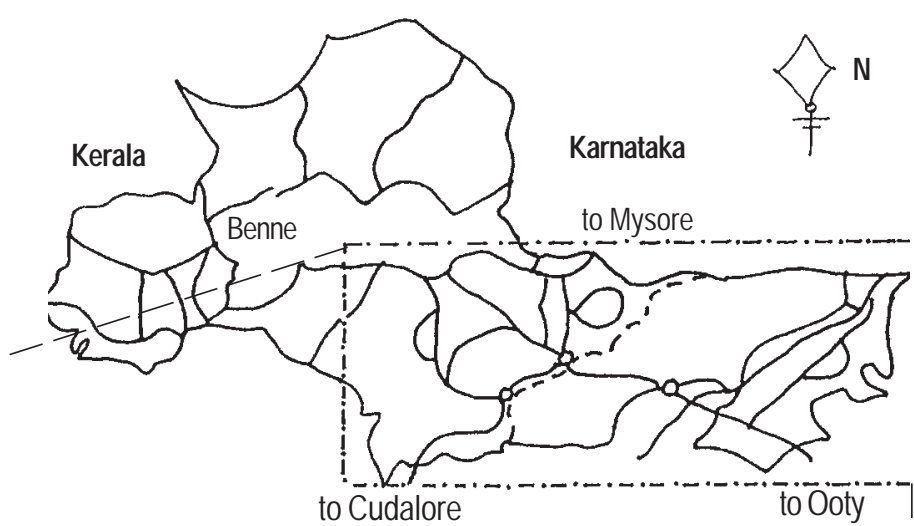

Figure 1. Map of Mudumalai Wildlife Sanctuary showing the study area 
transect for swampy grassland habitat.

Vehicle transect: Theppakadu -Mudumalai road, Cross cut road, Ombetta road, Game hunt road, Mudumalai-Kargudi road, Circular road and Ponnangiri road were selected in dry deciduous forest for the study. The Moyar road, Jayadev avenue and U road were covered for the scrub jungle. The Sand road and the Theppakadu-Kargudi road were used for riverine vehicle transect and Ombetta road was considered for the swampy grassland habitat.

\section{Observations and density calculations}

Observations were made between $0630 \mathrm{hrs}$ and $0900 \mathrm{hrs}$ and $1600 \mathrm{hrs}$ and $1830 \mathrm{hrs}$. The walking transects were surveyed by foot along with a field guide. A total of $48 \mathrm{~km}$ in dry deciduous forest, $48 \mathrm{~km}$ in scrub forest, $4 \mathrm{~km}$ in riverine forest and $36 \mathrm{~km}$ in swampy grassland were covered. For vehicle transects, a total of $53 \mathrm{~km}$ in dry deciduous forest, $100 \mathrm{~km}$ in scrub forest, $55 \mathrm{~km}$ in the riverine forest and $12 \mathrm{~km}$ in swampy grassland were covered. In each transect, the total number of animals sighted were recorded. The density (D) was calculated by using the formula

$\mathrm{D}=\mathrm{N} / \mathrm{A}$

where $\mathrm{N}=$ number of animals counted

$$
\mathrm{A}=\text { area scanned }
$$

The area scanned was calculated by multiplying the total distance covered into mean visibility for each habitat and species. The visibility readings were of meter scale which was converted into kilometer for final density estimation.

To find out visibility in all transects, trees along the transects were marked with red paint at $50 \mathrm{~m}$ intervals and visibility observations were made on the left and the right side of the transects. Using these visibility readings mean visibility was calculated. As visibility for different sized animals vary, separate

Table 1. Visibility of animals under observation, the distance covered and area scanned in the various habitats of the study area

\begin{tabular}{llllll}
\hline & & D.D.F & Scrub & Riverine & S.G \\
\hline Visibility $(\mathrm{m})$ & 1 & 286 & 185 & 196 & 200 \\
& 2 & 190 & 139 & 130 & 200 \\
Distance & W & 48 & 48 & 44 & 36 \\
covered $(\mathrm{km})$ & V & 253 & 100 & 55 & 12 \\
Area scanned & 1 & 13.7 & 8.6 & 8.9 & 7.2 \\
$\left(\mathrm{~km}^{2}\right)$ & 2 & 9.1 & 5.7 & 6.7 & 7.2 \\
\hline
\end{tabular}

Visibility and area scanned: 1 - For Elephant and Gaur; 2 - For Axis Deer and Sambar; W - Walking transect; $\vee$ - Vehicle transect; SG - Swampy grassland visibility measurements were made for large and medium-size mammals. Elephants and Gaurs were considered large mammals and Axis deer and Sambar medium-sized mammals.

\section{Density of large mammals in different habitats and comparison of walking and vehicle transects}

Walking transect results showed a decreasing Spotted Deer density in the descending order from the scrub jungle to swampy grassland, dry deciduous forests and the least being in riverine habitats. Vehicle transect estimates also showed more or less similar trend; higher densities in scrub jungle followed by dry deciduous, swampy grassland and riverine forests (Table 2).

Sambar Deer was distributed in all habitats. High density of Sambar was encountered in dry deciduous forest. In scrub jungle and riverine habitats, the density was found to be two animals/ $\mathrm{km}^{2}$ and was reduced to only one animal $/ \mathrm{km}^{2}$ in the swampy area. Vehicle transect estimates showed lower densities of Sambar in all habitats.

The walking transect studies revealed that the density of Elephants was high in swampy areas and they were not seen in scrub jungle during the study period. Vehicle transects estimation also showed higher densities of Elephants in swampy area than in other habitats. Gaur density was found to be very low in all habitats in both walking and vehicle transects estimations.

Comparison of walking and vehicle transect results revealed that Axis Deer and Sambar densities were constantly higher in the walking transects compared to the vehicle transect. Similarly,

Table 2. Density of large mammals in the various habitats estimated by walking transect.

\begin{tabular}{lllll}
\hline Species & D. D. F. & Riverine & Scrub & Swampy \\
\hline Spotted deer & 17.5 & 10.7 & 111.4 & 19.0 \\
Sambar & 6.3 & 1.9 & 2.4 & 0.8 \\
Elephant & 9.4 & 2.3 & - & 15.4 \\
Gaur & 1.2 & 0.2 & - & - \\
\hline
\end{tabular}

D.D.F - Dry Deciduous Forest; Density is expressed in $\mathrm{km}^{2}$

Table 3. Density of large mammals in the various habitats estimated by vehicle transects.

\begin{tabular}{lllll}
\hline Species & D. D. F & Riverine & Scrub & Swampy \\
\hline Spotted Deer & 9.2 & 0.8 & 42.4 & 5.8 \\
Sambar & 0.7 & 0.8 & 0.6 & 0.8 \\
Elephant & 1.7 & 2.8 & 0.7 & 17.4 \\
Gaur & 0.1 & 0.3 & - & 0.8 \\
\hline
\end{tabular}

D.D.F - Dry Deciduous Forest; Density is expressed in $\mathrm{km}^{2}$ 
Table 4. Effect of roads on the density of large mammals in dry deciduous forest as estimated by walking transects.

\begin{tabular}{lcc}
\hline Species & Inside the forest & Road side \\
\hline Spotted Deer & 47 & 122 \\
Sambar & 41 & 17 \\
Elephant & 86 & 43 \\
Gaur & 16 & - \\
\hline
\end{tabular}

The number indicates total number of animals seen for each species.
Table 5. Number of animals sighted during walking transect laid along road side and inside in scrub forest.

\begin{tabular}{lcc}
\hline Species & Inside the forest & Road side \\
\hline Spotted Deer & 691 & 316 \\
Sambar & 11 & 5 \\
Elephant & - & - \\
Gaur & - & - \\
\hline
\end{tabular}

The number indicates total number of animals seen for each species.
Gaur densities were higher in the walking transects in all the habitats except riverine, however, the difference was not much. Elephant density estimates by walking and vehicle transects were similar in the riverine and swampy habitats, but markedly different in the dry deciduous forest as seen from the ratio 9.4: 1.7 .

Comparison of results of walking and vehicle transects suggest that vehicle transects reduced the chances of sighting for most of the species, which could be due to noise which made the animals move away from the roadside into the forest. The difference could also be due to the fact that walking transects covered comparatively a small area than vehicle transects.

\section{Effect of roads on animal densities}

Results presented in Tables 4 and 5 show that roads affect animal density. The animals were either attracted to or driven away from the roadside.

The frequency distribution of number of animals sighted during the individual walking transects of inside and roadside were subjected to a statistical test (Mann-Whitney U test) for differences. The results for Spotted Deer shows that the density along the roadside is significantly higher than that found inside the dry deciduous forest $(\mathrm{U}=109, \mathrm{n} 1=\mathrm{n} 2=12, \mathrm{p}<0.05)$. In the scrub jungle, the differences were not significant at five per cent level, but significant only at 10 per cent level, where $\mathrm{U}=106, \mathrm{n}=$ $\mathrm{n} 2=12, \mathrm{p}<0.10$. For Sambar the density is higher inside the forest than along the road side, the test shows significant difference in the densities inside the forest and along the road side of dry deciduous forest $(\mathrm{U}=103, \mathrm{n} 1=\mathrm{n} 2=12, \mathrm{p}<0.10)$. The number of Elephants sighted inside the forest is twice than that seen along the roadside. However, due to relatively few sightings it was not possible to make a statistical test of significance for the observed difference. For all other animals and habitats the number of animals sighted was too less to carry out any statistical tests.

\section{Habitat utilization in relation to vegetation type}

An animal utilizes different habitats for meeting its food and water requirements, finding mates and in avoiding predators.
These requirements may also change with season and these patterns of habitat utilization can be reflected in density of these mammals in different habitats. Spotted Deer is known to be an animal of forest edge, they show strong affinity for open areas and areas near human habitation (Sharatchandra \& Gadgil, 1975). The density estimation of Axis Deer has shown that it prefers open scrub habitat, as the habitat is suitable for it's grazing and browsing requirements in different seasons. Since Spotted Deer do not show distinct seasonal movement over long distances, they may meet their forage requirements within any particular habitat type by suitably changing their grazing-browsing ratio (Prasad \& Sharatchandra, 1984)

It is known that Sambar adapts itself to a wide variety of habitats. However, a notable difference is seen in dry deciduous forest in which density is slightly higher. These deers are believed to be mainly browsers (Schaller, 1967) and the dry deciduous forest provides the browsing species, hence it can be expected that the density of the animal is more in deciduous forest.

Elephants show distinct seasonal movements over large distances. Their movement is strongly related to the availability of water and other resources (Sukumar, 1985). The present study shows that they show a strong affinity for the swamps during the dry seasons, this could be due to the presence of water and higher availability of grass in the swampy grassland. The results of density estimates of Gaur shows their presence in the focal study area was little during dry seasons.

\section{Evaluation of methods of censusing}

When animals such as Spotted Deer show a highly clumped distribution near human habitation or along the roadside a correct estimate of density may not be possible through vehicle transect. Similarly, Sambar are repelled from the roadside by vehicle noise and road transects would give underestimates for such species. It is best to use a combination of walking transect inside the forest supplemented by some road transects. In any case correction for density estimates along the roads will have to be done by estimating the extent of bias. When a species is present at a lower density, e.g., Elephant, the sampling effort through walking transect may be insufficient to estimate density since 
sightings of a large herd would give rise to false density estimates. On the other hand, covering a longer distance by vehicle is likely to give more precise or accurate results. Stratification of the study area by habitat type therefore becomes essential before a census, since animals also show strong seasonal affinities for particular habitats.

\section{Acknowledgements}

Dr. R. Sukumar, Centre for Ecological Sciences, Indian Institute of Science, Bangalore, technically and financially supported the study. Our gratitude is due to Prof. R. Kanakasabai, ex head of the department of Zoology, and other staff members of the department A.V.C. College, Mayiladuturai for their help and encouragement. We thank the Forest Department of Tamil Nadu for granting permission to carry out the study in Mudumalai Wildlife Sanctuary.

\section{References}

Anderson, D.R., J.L.Laake, B.R. Crain and K.P. Burnham (1979)

Guidelines for line transect sampling of biological population. Journal of Wildlife Management 43(1): 70-78.

Krishnan, M. (1972) An ecological survey of the larger mammals of Peninsular India. Bombay Natural History Society, Mumbai.

Prasad S.N. and H.C. Sharatchandra (1984) Primary production and consumption in the deciduous forest ecosystems of Bandipur in south India. Proceedings of the Indian Academy of Sciences (Plant Science): 83-87.

Sale, J.B. and A.J.T. Johnsingh (1988). Counting Asian Elephant. A technical report, Wildlife Institute of India, Dehra Dun.

Schallar, G.B. (1967). The Deer and the Tiger. University of Chicago Press, Chicago.

Sharatchandra, H.C. and M. Gadgil. (1975). A year of Bandipur. Journal of the Bomay Natural History Society 72(3).

Sukumar, R. (1985). Ecology of the Asian Elephant (Elephus maximus) and its interaction with man in south India. Ph.D. Thesis, Indian Institute of Science, Bangalore (Unpublished). 